\title{
Síntese e Caracterização de Copolímeros à Base de Metacrilato de Metila e Divinilbenzeno com Propriedades Magnéticas
}

\author{
Cristiane N. Costa, Marcos A. S. Costa, Luiz C. de S. Maria \\ Laboratório de Química de Polímeros, UERJ \\ Manoel R. Silva \\ Departamento de Física e Química, UNIFEI \\ Fernando G. Souza Jr., Ricardo Michel \\ Instituto de Macromoléculas Professora Eloisa Mano, UFRJ
}

\begin{abstract}
Resumo: Neste trabalho, foram sintetizados materiais binários baseados em copolímeros de metacrilato de metila reticulados com divinilbenzeno contendo partículas de ferro com propriedades magnéticas pela técnica de polimerização em suspensão. Foram estudados os efeitos da concentração de ferro adicionado na polimerização, da razão molar MMA/DVB, do tipo de agente de suspensão e da velocidade de agitação na formação do copolímero. Os copolímeros foram caracterizados quanto à morfologia, à estabilidade térmica, ao teor de ferro incorporado, à distribuição de tamanho de partículas, às propriedades magnéticas, à área superficial, ao volume e ao tamanho de poros. Foram obtidas microesferas poliméricas com propriedades magnéticas que apresentaram bom controle morfológico esférico e partículas de ferro aglomeradas por toda a superfície da microesfera. As análises de propriedades magnéticas mostraram que os materiais obtidos não apresentaram ciclos de histerese, estando assim próximos de um material com propriedades superparamagnéticas, com magnetização de saturação entre 8,0 e 13,0 emu.g ${ }^{-1}$.
\end{abstract}

Palavras-chave: Copolímero de metacrilato de metila e divinilbenzeno, propriedades magnéticas, ferro.

\section{Synthesis and Characterization of Copolymers Based on Methyl Methacrylate and Divinylbenzene with Magnetic Properties}

\begin{abstract}
In this work, copolymers based on methyl methacrylate and divinylbenzene containing iron with magnetic properties were produced using the suspension polymerization method. An investigation was performed of the effect from the concentration of iron added to the polymerization, the MMA/DVB molar ratio in the copolymer formation, type of suspension agent and stirring speed on the synthesis of the copolymers. The copolymers morphology, thermal stability, contents of embedded iron, particle size distribution, magnetic properties, surface area, volume and pore size were evaluated. Polymeric microspheres with magnetic properties were successfully obtained. These materials showed good control of the spherical shape and agglomeration of iron particles under the surface of the microsphere. The analysis of magnetic properties pointed to materials with no hysteresis loops, thus being close to a material with superparamagnetic properties with saturation magnetization between 8.0 and 13.0 emu. $\mathrm{g}^{-1}$.
\end{abstract}

Keywords: Copolymer of methyl methacrylate and divinylbenzene, magnetic properties, iron.

\section{Introdução}

Esferas de polímeros magnéticas são compostas por nano ou micropartículas magnéticas incorporadas em uma matriz polimérica. O tamanho das esferas pode variar de centenas de nanômetros a alguns milímetros. De acordo com o método de preparo, diferentes tipos de esferas podem ser obtidas. Em um tipo as partículas magnéticas são homogeneamente distribuídas no volume da matriz polimérica. Em outros, são formadas estruturas do tipo casca e núcleo (polímero -núcleo e material magnético - casca) ou (material magnético - núcleo e polímero - casca). As propriedades magnéticas das esferas poliméricas são determinadas pelas partículas magnéticas que estão presentes. Entre estas partículas os óxidos são preferidos sobre os metais puros $\mathrm{Fe}_{3} \mathrm{O}_{4}, \mathrm{Fe}_{2} \mathrm{O}_{3}$, ferro, níquel e cobalto, pois são mais estáveis a oxidações ${ }^{[1-5]}$.

As microesferas poliméricas magnéticas têm despertado grande interesse e aplicação nos campos da biotecnologia e da medicina nos últimos anos, uma vez que podem ser separadas e recolhidas do meio com a aplicação de um campo magnético. Sua utilização obedece ao fenômeno de adsorção, similar às microesferas poliméricas não magnéticas, onde substâncias são retiradas do meio por um adsorvente sólido. São adequadas para aplicação nas áreas de isolamento de células, imobilização e purificação de enzimas e proteínas, suporte para drogas no tratamento de células alvo e remoção de contaminantes orgânicos na fase aquosa ${ }^{[1,5,6]}$. Recentemente, microesferas poliméricas magnéticas têm sido utilizadas para biorremediação de águas e solos contaminados com fenol em substituição a fase líquida dos biorreatores de duas fases de particionamento, eliminando assim os desafios operacionais ${ }^{[7]}$.

A síntese de microesferas de poli(metacrilato de metila) (PMMA) com propriedades magnéticas tem sido descrita na literatura $^{[1,8]}$. Por exemplo, Chen e colaboradores ${ }^{[8]}$ empregaram magnetita modificada com ácido oleico para a obtenção de microesferas de PMMA reticuladas com divinilbenzeno com comportamento de material superparamagnético e com bom controle morfológico. A literatura descreve também a importância das microesferas poliméricas com propriedades magnéticas à base de metacrilato de metila e divinilbenzeno no campo da biomedicina,

Autor para correspondência: Marcos A. S. Costa, Laboratório de Química de Polímeros, Universidade do Estado do Rio de Janeiro - UERJ,

Rua São Francisco Xavier, 524, Maracanã, PHLC, 3 andar, CEP 20550-900, Rio de Janeiro, RJ, Brasil, e-mail: marcoscosta.iq.uerj@gmail.com 
principalmente na área de transporte enzimático e também na área ambiental. Entretanto, a maioria dos poucos artigos encontrados dá maior ênfase ao estudo da aplicação desses materiais do que a sua síntese e caracterização ${ }^{[9-11]}$. Sendo assim, o presente trabalho tem como objetivo estudar alguns efeitos de parâmetros de síntese sobre a copolimerização de metacrilato de metila e divinilbenzeno por polimerização em suspensão na presença de partículas de ferro.

\section{Experimental}

\section{Preparo da fase aquosa}

Em balão de $500 \mathrm{~mL}$ ou de $1000 \mathrm{~mL}$, de fundo redondo com três bocas, provido de agitador mecânico e condensador de refluxo, água destilada e deionizada foi colocada sob agitação mecânica constante de $400 \mathrm{rpm}$ e aquecimento de $90{ }^{\circ} \mathrm{C}$. Em seguida, foram adicionados a gelatina (Royal produtos alimentícios Ltda.) como agente de suspensão $\left(0,1 \%\right.$ p/v), $\mathrm{CaCO}_{3}$ (Merck S.A.) $\left(1 \%\right.$ p/v) e $\mathrm{Na}_{2} \mathrm{SO}_{4}$ (Vetec Química Fina Ltda.) $(6 \%$ p/v), sal responsável pelo efeito "salting out". O volume da fase aquosa (FA) preparada corresponde a três vezes o volume de fase orgânica $(\mathrm{FO})^{[12]}$.

\section{Preparo da fase orgânica}

Os monômeros metacrilato de metila (MMA) (Metacril do Brasil S.A) e divinilbenzeno (DVB) (Nitriflex), o iniciador peróxido de benzoíla (BPO) (Vetec Química) e o diluente n-heptano (Vetec Química) foram usados como recebidos. Inicialmente, adicionou-se a mistura de monômeros metacrilato de metila e divinilbenzeno (razão molar 50/50\%) em um balão de fundo redondo com três bocas, sob agitação magnética branda e na temperatura ambiente. Em seguida, foi adicionado o iniciador peróxido de benzoíla (BPO) na concentração de $1 \%$ em relação ao número de moles total de monômeros. O balão foi fechado e uma saída lateral acoplada a um condensador de bolas para refluxo. Este sistema foi colocado em banho termostático à temperatura de $50{ }^{\circ} \mathrm{C}$ por $30 \mathrm{~min}$ (pré-polimerização). Após o tempo de pré-polimerização, com o sistema ainda sob agitação, foi adicionado n-heptano (diluente não solvatante, grau de diluição $100 \%$ ) e a agitação mantida por mais 10 min para completa solubilização. Em seguida, adicionou-se o ferro como material magnético (Carbonyl Iron Powder OX - Basf, com tamanho médio de $4 \mu \mathrm{m}$, recoberto com 5-10\% de $\mathrm{Fe}_{2} \mathrm{O}_{3}$ ) na concentração desejada em relação ao volume total de monômeros. O material magnético foi disperso na fase orgânica com auxílio de um ultrassom e velocidade $13000 \mathrm{rpm}$. Essa mistura final compõe a fase orgânica ${ }^{[12]}$.

\section{Polimerização em suspensão}

A fase orgânica (monômeros + iniciador + ferro), previamente preparada foi adicionada em um balão de 3 bocas de $500 \mathrm{~mL}$ contendo a fase aquosa, em temperatura ambiente sob agitação mecânica de $400 \mathrm{rpm}$, dando origem a uma suspensão aquosa. Esta suspensão foi mantida a $90{ }^{\circ} \mathrm{C}$, por 24 horas, procedendo assim à polimerização em suspensão convencional. Em seguida, as microesferas poliméricas obtidas foram purificadas e secas em estufa a $60{ }^{\circ} \mathrm{C}$. Em seguida, foi transferido para um peneirador (Retsch, modelo AS 2000 basic) onde foi separado. A faixa granulométrica que resultou na maior quantidade de microesferas $(0,75 \mathrm{~mm})$ foi utilizada nas caracterizações do material ${ }^{[12]}$.

\section{Caracterização dos copolímeros}

As características magnéticas dos copolímeros foram analisadas por VSM (Lake Shore, modelo Série 7400), onde cerca de 0,05 g de amostra foram adicionados ao aparelho e o campo magnético aplicado variou de $-14000 \mathrm{G}$ a $14000 \mathrm{G}$. O tempo total de cada análise foi de 10 minutos, sendo os dados coletados a cada segundo. A degradação térmica dos materiais foi avaliada por TGA/DTGA (TA Instruments, modelo Q50 V6.4 Build 193), onde cerca de $10 \mathrm{mg}$ de amostra foram colocadas em uma cápsula de platina que foi aquecida em atmosfera de nitrogênio com uma vazão de $100 \mathrm{~mL} / \mathrm{min}$, de 50 a $650{ }^{\circ} \mathrm{C}$ a uma velocidade de $20{ }^{\circ} \mathrm{C} / \mathrm{min}$. A morfologia dos materiais foi analisada por microscopia ótica de reflexão (modelo LGPS2), onde as amostras foram colocadas em uma lâmina de vidro e submetidas à ação de um feixe luminoso para observação; e por SEM (Carl Zeiss do Brasil, modelo Leo $1450 \mathrm{VP}$ ), onde as amostras foram revestidas por uma fina camada de ouro para aumentar sua condutividade e proteger contra o aquecimento localizado. A seguir, a amostra preparada interagiu com elétrons secundários, em alto vácuo, sob uma tensão de aceleração de $20 \mathrm{kV}$. A quantidade de ferro incorporado foi determinada por absorção atômica (Marca Perkin Elmer, modelo Analyst 300). Cerca de 0,0100 g de amostra foi transferida para um balão de $100 \mathrm{~mL}$ acoplado a um condensador de refluxo e, em seguida, adicionaram-se $20 \mathrm{~mL}$ de água régia (mistura 1:3 em volume de ácido nítrico e ácido clorídrico), aquecendo-se a mistura na temperatura de refluxo por 24 horas. Depois de resfriada, a solução foi filtrada em funil de vidro e lavada com $40 \mathrm{~mL}$ de água destilada. Todo o eluente foi recolhido em um balão volumétrico de $100 \mathrm{~mL}$ que foi avolumado com água destilada. A área específica, volume e diâmetro médio dos poros foram determinados por adsorção de nitrogênio utilizando as técnicas descritas por BET e $\mathrm{BJH}$, respectivamente através do equipamento ASAP 2020 V3. $01 \mathrm{E}$.

\section{Resultados e Discussões}

\section{Efeito da concentração de ferro adicionado na polimerização}

Nas sínteses dos copolímeros, os teores de ferro variaram de 2,5 a $15 \%$ m/v (em relação ao volume de monômeros), e os demais parâmetros reacionais foram mantidos constantes. A Tabela 1 mostra o efeito da variação de ferro empregado (\% p/v, em função do volume de monômeros) na polimerização sobre o teor de ferro incorporado. Esta tabela também mostra o efeito da quantidade de ferro incorporada sobre a magnetização de saturação, a magnetização remanescente e a coercividade dos materiais obtidos. Observa-se que o maior teor de ferro incorporado nas pérolas de copolímero e o maior rendimento de reação de polimerização foram alcançados quando se adicionou 7,5\% de ferro na polimerização. Os resultados mostram que a quantidade de ferro incorporado diminuiu quando o percentual de ferro adicionado foi para 10,0 e 15,0\%.

Como mostrado na Figura 1, de um modo geral, todos os copolímeros apresentaram o mesmo perfil. A Figura 1a apresenta as curvas de TGA do copolímero de MMA/DVB sintetizado com $7,5 \%$ de ferro. Pode ser observado que este copolímero apresentou um resíduo de aproximadamente $0,40 \mathrm{mg}$, enquanto que o copolímero sintetizado sem adição de ferro apresentou um resíduo de aproximadamente $0,28 \mathrm{mg}$. Os copolímeros sintetizados com 5 e $15 \%$ de ferro apresentaram resíduos de 0,28 e $0,36 \mathrm{mg}$, respectivamente. Estes resultados corroboram com os teores de ferro determinados por absorção atômica, ou seja, um aumento na concentração de ferro adicionada, não proporcionou um aumento equivalente no teor de ferro incorporado (aumento no teor de resíduo total). Foi observada também uma única zona térmica de perda de massa, relativa à decomposição da matriz polimérica, e um único pico de DTGA relacionado a esse estágio de decomposição. Observa-se que todos os copolímeros de MMA-DVB apresentam perfis semelhantes de termodegradação. A curva de TGA do copolímero MMA-DVB sem ferro (Figura 1b) apresentou a 
Tabela 1. Influência da variação de ferro adicionado, da razão molar MMA/DVB, do agente de suspensão e da velocidade de reação na síntese dos copolímeros.

\begin{tabular}{|c|c|c|c|c|c|c|c|c|}
\hline $\begin{array}{c}\text { Razão } \\
\text { MMA/ } \\
\text { DVB } \\
(\% \\
\text { molar })\end{array}$ & $\begin{array}{c}\text { Velocidade } \\
\text { de } \\
\text { reação } \\
(\text { rpm })\end{array}$ & $\begin{array}{c}\text { Agente } \\
\text { de } \\
\text { suspensão } \\
(0,1 \% \text { da FA) }\end{array}$ & $\begin{array}{c}\text { Ferro } \\
\text { Adiciona- } \\
\text { do } \\
\text { (\% em relação } \\
\text { a quantidade de } \\
\text { monômeros) }\end{array}$ & $\begin{array}{c}\text { Ferro } \\
\text { incorporado } \\
\text { (mg Fe/g de } \\
\text { copolímero)* }\end{array}$ & $\begin{array}{l}\mathbf{H}_{\mathrm{C}} \\
(\mathbf{G})\end{array}$ & $\begin{array}{c}M_{s} \\
(\text { emu.g } \\
\left.{ }^{-1}\right)\end{array}$ & $\begin{array}{c}M_{R} \\
\left(\mathrm{emu} \cdot \mathrm{g}^{-1}\right)\end{array}$ & $\begin{array}{c}\text { Rendimen- } \\
\text { to } \\
(\%)\end{array}$ \\
\hline $50 / 50$ & 400 & gelatina & Branco & -- & --- & -- & -- & \\
\hline $50 / 50$ & 400 & gelatina & 2,5 & 18,0 & 74,2 & 3,7 & 0,104 & 63 \\
\hline $50 / 50$ & 400 & gelatina & 5,0 & 35,7 & 89,1 & 2,7 & 0,229 & 76 \\
\hline $50 / 50$ & 400 & gelatina & 7,5 & 52,2 & 69,6 & 8,8 & 0,308 & 77 \\
\hline $50 / 50$ & 400 & gelatina & 10,0 & 49,3 & 49,4 & 5,8 & 0,097 & 72 \\
\hline $50 / 50$ & 400 & gelatina & 15,0 & 36,4 & 55,5 & 5,2 & 0,112 & 68 \\
\hline $50 / 50$ & 400 & gelatina & 7,5 & 55,3 & 46,7 & 5,9 & 0,028 & 58 \\
\hline $50 / 50$ & 400 & PVA & 7,5 & 16,5 & 68,0 & 1,9 & 0,308 & 66 \\
\hline $50 / 50$ & 400 & 2-Hidroxietilcelulose & 7,5 & 24,7 & 45,0 & 5,3 & 0,069 & 79 \\
\hline $50 / 50$ & 500 & gelatina & 7,5 & 57,0 & 25,1 & 13,0 & 0,081 & 75 \\
\hline
\end{tabular}

*Determinado por absorção atômica; Hc - Força Coerciva; Ms - Magnetização de saturação; MR - Magnetização remanescente; Ferro adicionado = Carbonyl iron powder OX com MS = 182,0 emu.g-1 e MR = 0,824 emu.g-1.
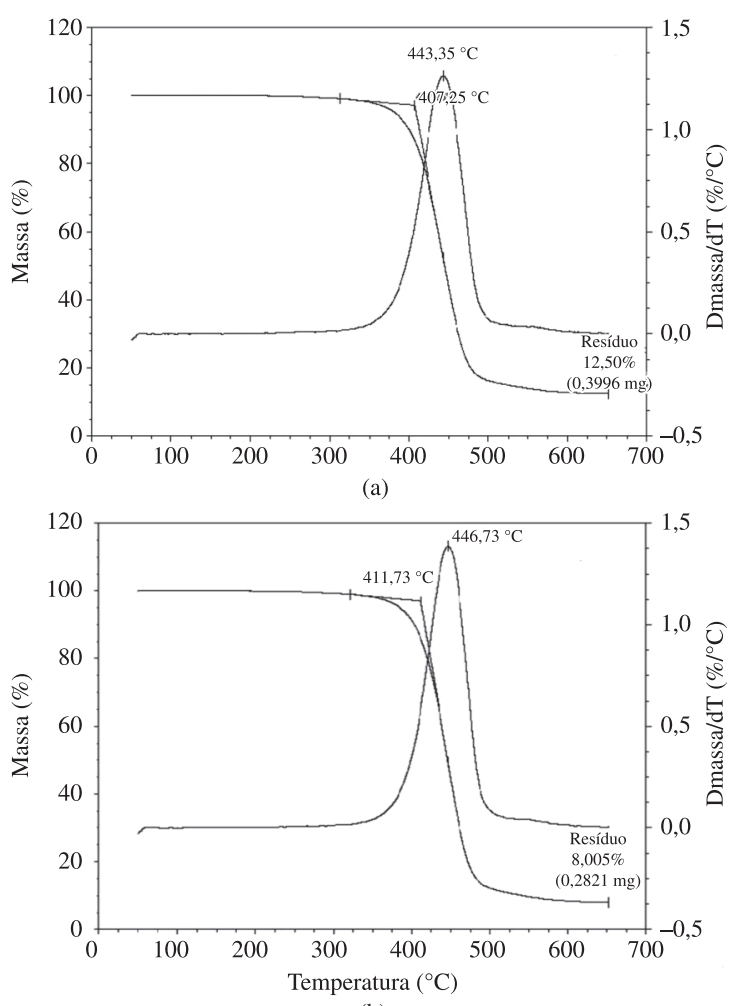

(b)

Figura 1. Curva de TGA (a) do copolímero sintetizado com $7,5 \%$ de ferro adicionado (em função da quantidade de monômeros); (b) Curva de TGA do copolímero sintetizado sem ferro (branco)

degradação inicial em $447{ }^{\circ} \mathrm{C}$. Foi observado que a temperatura de degradação dos copolímeros sintetizados com ferro não foi afetada pela presença do material magnético e a estabilidade térmica dos copolímeros manteve-se estável.

$\mathrm{O}$ aspecto morfológico das microesferas foi avaliado por microscopia eletrônica de varredura e microscopia ótica. As micrografias de microscopia ótica (Figuras 2a) apresentam o aspecto visual externo dos materiais polimérico obtido em função da concentração de ferro adicionado na polimerização. De uma forma geral, todos os copolímeros de MMA-DVB apresentaram esse mesmo perfil morfológico. Nota-se ainda que o tamanho das pérolas não são uniformes e existem diferenças de coloração entre as pérolas, mostrando a heterogeneidade da distribuição de ferro nas microesferas. A Figura $2 \mathrm{c}$ apresenta a micrografia de microscopia eletrônica de varredura do copolímero, mostrando o perfil da superfície externa e a Figura 2 d mostra o perfil da superfície interna deste copolímero. É possível observar que existem algumas aglomerações de partículas de ferro em pontos distintos da superfície externa dos copolímeros. No entanto, não se pode afirmar que haja partículas de ferro no interior das pérolas dos copolímeros. As superfícies internas não apresentam diferenças significativas com o aumento da concentração de ferro adicionado na polimerização. A superfície interna dos copolímeros apresentou-se geralmente mais porosa que a superfície externa. No interior das pérolas, pode-se observar a formação de aglomerados de microesferas de diferentes tamanhos. Por outro lado, na superfície, os domínios poliméricos são estruturas compactas e sem forma definida. Estas diferenças morfológicas entre a superfície externa e o interior das pérolas são características comuns de polímeros reticulados macroporosos sintetizados através de polimerização em suspensão. A maior compactação dos domínios poliméricos na superfície do que no interior das pérolas tem sido atribuída a um efeito de compressão devido à tensão interfacial entre a fase orgânica e a fase aquosa durante a polimerização em suspensão ${ }^{[10]}$. A utilização do n-heptano (não solvente) provocou um aumento dos tamanhos dos macroporos das microesferas e seus aglomerados no interior das pérolas.

A Tabela 1 apresenta também os valores de magnetização, observa-se um maior valor de magnetização de saturação para o copolímero sintetizado com $7,5 \%$ de ferro. Este fato pode ser explicado devido à maior incorporação de ferro na matriz polimérica. A Figura 3a apresenta a curva de magnetização para este copolímero. É possível verificar que não houve a formação do ciclo de histerese. As curvas de magnetização para todos os copolímeros sintetizados apresentaram perfis similares sem formação de histerese, fenômeno que causa o atraso entre a densidade de fluxo magnético e o campo magnético. Além disso, nota-se que os valores de magnetização remanescente foram próximos de zero indicando que esses copolímeros estão próximos de um material com propriedades superparamagnéticas. A literatura apresenta valores de magnetização de saturação encontrados na faixa de 15 a 17 emu. ${ }^{-1[13]}$. No entanto, Lee e colaboradores ${ }^{[4]}$ obtiveram materiais com magnetizações de saturação na faixa de 1,2 e 4,0 emu.g ${ }^{-1}$ que, segundo os autores, 


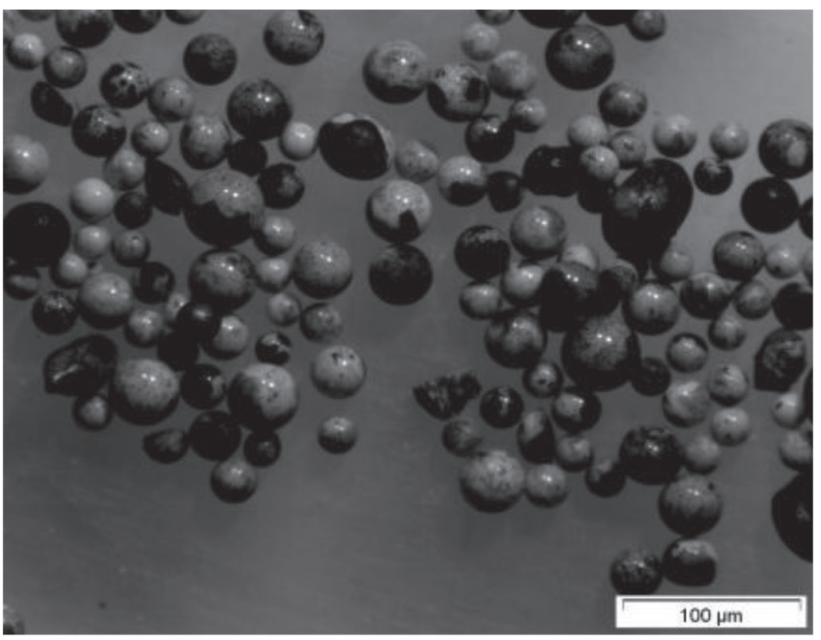

(a)

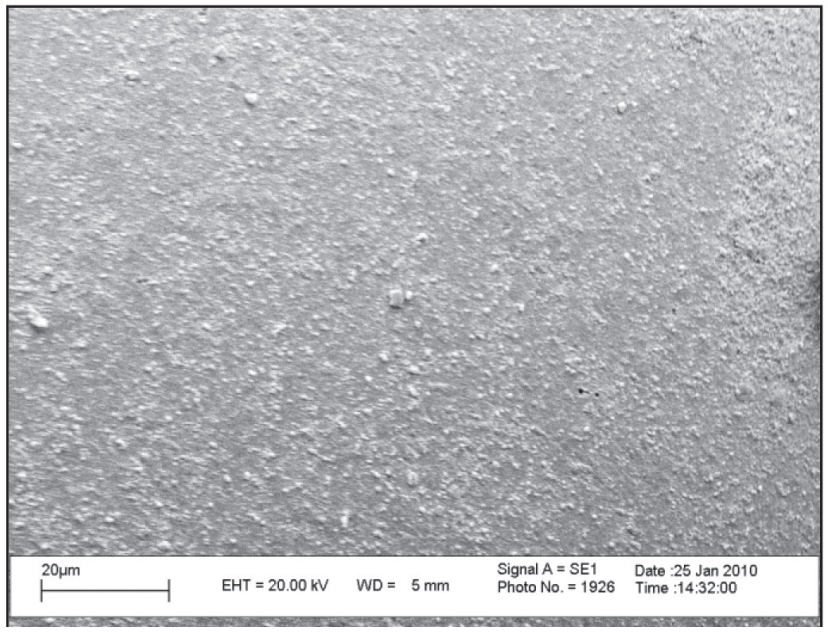

(c)

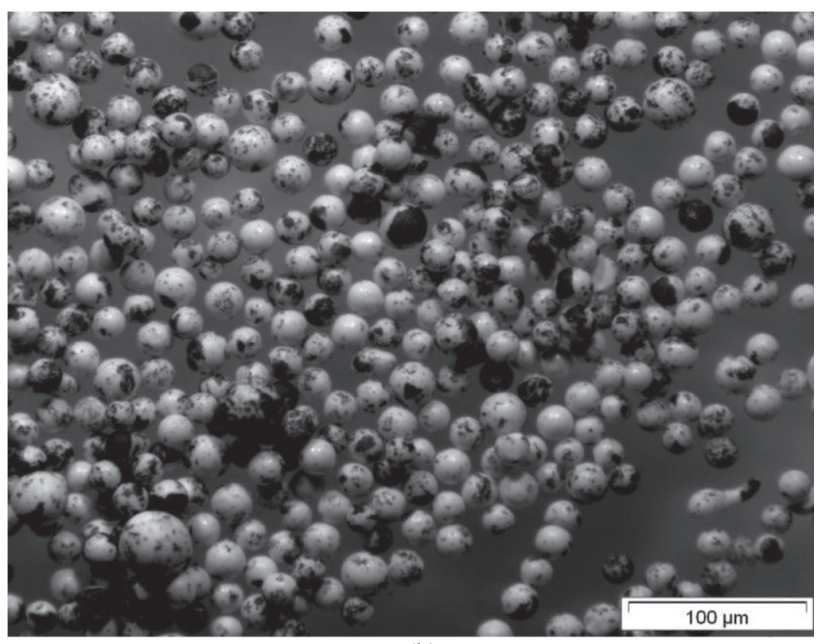

(b)

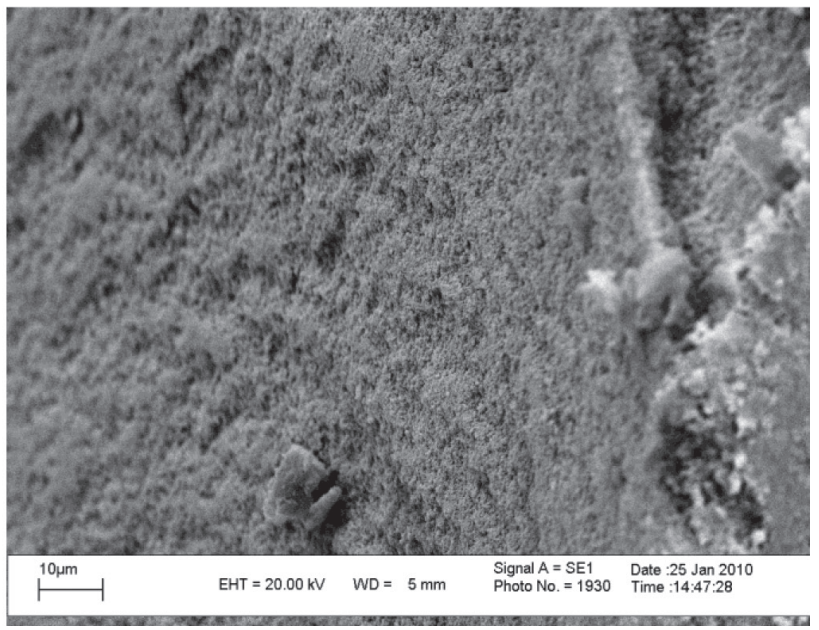

(d)

Figura 2. Micrografia de microscopia ótica, aumento de 20× dos copolímeros sintetizados com (a) 7,5\% de ferro e velocidade de agitação de 400 rpm; (b) $7,5 \%$ de ferro e velocidade de agitação de 500 rpm; Micrografia de microscopia eletrônica de varredura, aumento de 3000× e velocidade de agitação de $400 \mathrm{rpm}$ (c) superfície externa do copolímero com 7,5\% de ferro (d) superfície interna do copolímero com 7,5\% de ferro

esses resultados de magnetização de saturação seriam adequados para sua utilização como resinas de troca iônica com propriedades magnéticas. Estes resultados indicam uma possível utilização dos materiais obtidos neste estudo para a produção de resinas de troca iônica com propriedades magnéticas.

\section{Influência da razão molar MMA/DVB na formação do copolímero de metacrilato de metila e divinilbenzeno}

A razão molar de monômeros MMA/DVB foi variada em 50/50, 75/25 e 25/75. Todos os outros parâmetros foram mantidos constantes. A quantidade de ferro adicionado foi 7,5\% em relação à quantidade total de monômeros. Pode-se observar que o aumento da concentração de MMA não foi favorável à formação de microesferas. Este comportamento era esperado uma vez que um teor menor de DVB produz um material menos reticulado, e a fase MMA em maior quantidade, que apresenta maior afinidade com o solvente utilizado do que o DVB, que gera uma maior expansão da rede $^{[9]}$.

A observação da micrografia de microscopia eletrônica de varredura revela aglomerações de partículas de ferro em pontos distintos da superfície externa dos copolímeros como no copolímero sintetizado com razão molar MMA/DVB 50/50 (Figura 2c). No entanto, também não se pode afirmar que haja partículas de ferro no interior desses copolímeros.

A Tabela 1 também apresenta os resultados de incorporação de ferro e medidas de magnetização para esses copolímeros. É possível observar que, ao se aumentar o teor de DVB na composição do copolímero, houve um aumento na incorporação de ferro, e a magnetização de saturação diminuiu. Normalmente, quanto maior a incorporação de ferro maior será o valor de magnetização de saturação. No entanto, a magnitude de Hc e de Ms é afetada pelo tamanho das partículas e pela homogeneidade de cada material. Isso explica os resultados de incorporação de ferro, Ms e Hc obtidos nos copolímeros com razão molar MMA/DVB 25/75 e 50/50. Como os materiais sintetizados são heterogêneos, a distribuição de ferro no copolímero não é uniforme, podendo se encontrar pontos com diferentes quantidades de ferro.

Nenhum copolímero apresentou ciclo de histerese. O valor da magnetização remanescente $\left(\mathrm{M}_{\mathrm{R}}\right)$ foi próximo de zero indicando que este copolímero também está próximo de um material com propriedades superparamagnético.

A influência da razão molar MMA/DVB sobre a área específica, o volume e o tamanho de poros das partículas está apresentada na 


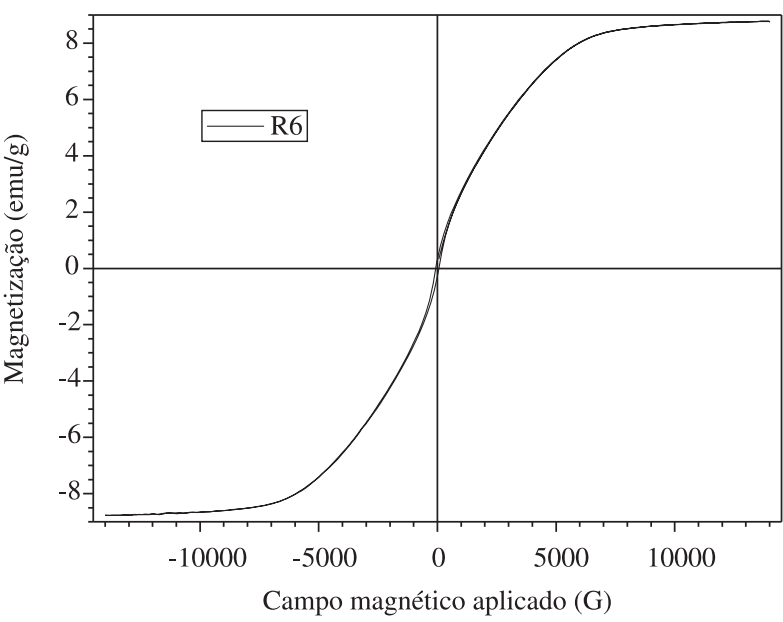

(a)

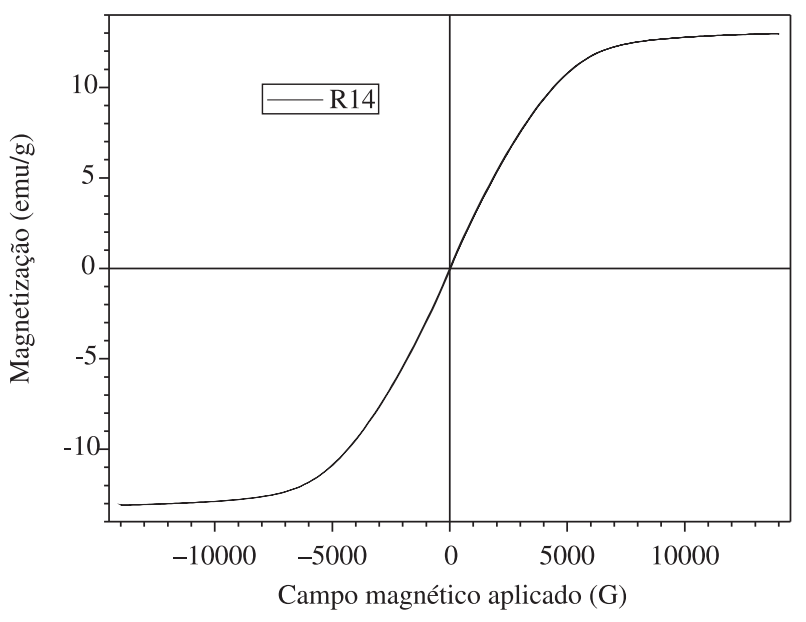

(b)

Figura 3. Curvas de magnetização dos copolímeros (a) sintetizado com razão MMA/DVB 50/50, velocidade agitação 400 rpm, gelatina e 7,5\% de ferro; (b) sintetizado com razão MMA/DVB 50/50, velocidade agitação 500 rpm, gelatina e 7,5\% de ferro

Tabela 1. Verifica-se que a faixa de tamanho de poros encontrado é estreita $(70$ e $75 \AA)$ e bem definida. Esse resultado pode ser explicado pela utilização de n-heptano (100\%). O solvente de baixa afinidade faz com que a rede polimérica permaneça na conformação mais enovelada quando da presença do solvente, mantendo essa porosidade no estado seco. Foi observado também que o aumento do teor de DVB na composição da fase monomérica gera estruturas com maiores valores de área específica como consequência do aumento do grau de reticulação promovido pelo DVB. Para resinas à base de MMA e DVB, a área, de modo geral, aumenta quando o volume de poros também aumenta. Este fato pode ser explicado com base no uso de um monômero mais polar, neste caso, o MMA.

Na Figura 4, são apresentadas as isotermas de adsorção de nitrogênio dos copolímeros sintetizados com diferentes razões molares MMA/DVB na presença ou não de ferro. Essas curvas assemelham-se à isoterma do tipo IV, típico de sólidos mesoporosos e macroporosos, nos quais o processo de evaporação é diferente do processo de condensação ${ }^{[14]}$, e que o aumento do teor de DVB na composição da fase monomérica gerou estruturas com maiores valores de área específica como consequência do aumento do grau de reticulação promovido pelo DVB. A área, de modo geral, aumentou quando o volume de poros também aumentou. Este fato pode ser explicado com base no uso de um monômero polar (MMA). Este fato pode gerar uma gota de fase orgânica menos coesa o que poderia facilitar a fuga do diluente (n-heptano) que apresenta afinidade pela fase aquosa reduzindo a quantidade de diluente na fase orgânica.

A curva de TGA para o copolímero sintetizado com razão molar de MMA/DVB 25/75 também apresentou uma única zona térmica de perda de massa, relativa à decomposição da matriz polimérica, e um único pico de DTGA relacionado a esse estágio de decomposição $\left(455^{\circ} \mathrm{C}\right)$. A temperatura de degradação do copolímero foi afetada pelo aumento do teor de DVB, porém essa alteração foi positiva, ou seja, o aumento do teor de DVB aumentou a estabilidade térmica do copolímero devido ao aumento na temperatura de degradação quando comparada à temperatura de degradação do copolímero sintetizado com razão molar 50/50 de MMA/DVB e 7,5\% de ferro adicionado $\left(443^{\circ} \mathrm{C}\right)$.

\section{Efeito do tipo de agente de suspensão na síntese dos copolímeros}

Os copolímeros foram sintetizados de forma idêntica, diferindo apenas na constituição da fase aquosa (FA) utilizada durante a síntese. A FA do copolímero foi constituída da seguinte forma:

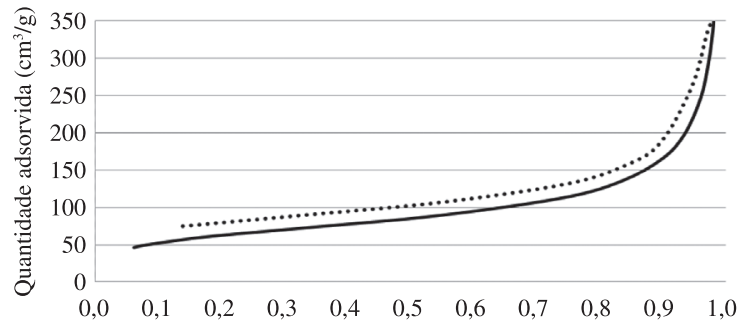

(a)

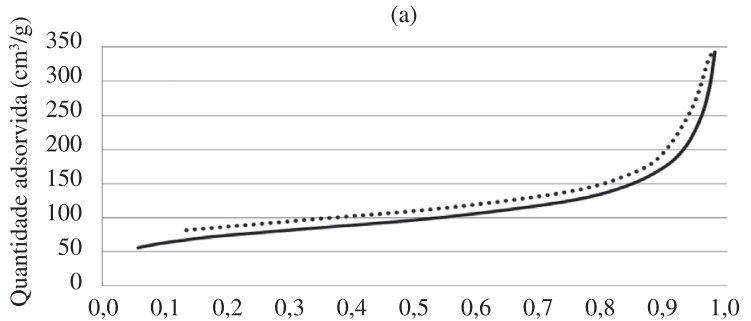

(b)

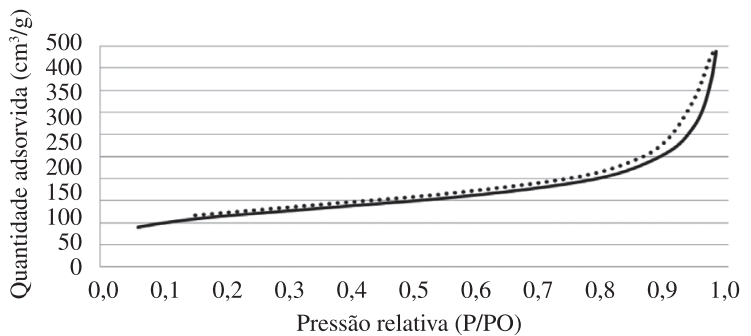

(c)

— Adsorção $\quad$ …... Dessorção

Figura 4. Isoterma de adsorção de nitrogênio dos copolímeros sintetizados com diferentes razões molares MMA/DVB: a) $25 / 75$ e $7,5 \%$ de ferro; b) $50 / 50$ e $7,5 \%$ de ferro; c) 50/50 sem adição de ferro.

- $0,1 \%$ de gelatina (p/v), $\mathrm{CaCO}_{3}(1 \% \mathrm{~m} / \mathrm{v}), \mathrm{Na}_{2} \mathrm{SO}_{4}(6 \% \mathrm{~m} / \mathrm{v})$;

- poli(álcool vinilico) $(0,1 \% \mathrm{~m} / \mathrm{v}), \mathrm{CaCO}_{3}(1 \% \mathrm{~m} / \mathrm{v}), \mathrm{Na}_{2} \mathrm{SO}_{4}$ $(6 \% \mathrm{~m} / \mathrm{v}) ; \mathrm{e}$

- $0,1 \%$ de hidroxietilcelulose, $\mathrm{CaCO}_{3}(1 \% \mathrm{~m} / \mathrm{v}), \mathrm{Na}_{2} \mathrm{SO}_{4}(6 \% \mathrm{~m} / \mathrm{v})$.

A quantidade de ferro adicionado na síntese foi mantida em 7,5\%. A distribuição de partículas foi mais homogênea para o copolímero sintetizado com gelatina. Este comportamento se deve, provavelmente, ao fato da gelatina ter estabilizado melhor 
Tabela 2. Influência da razão molar MMA/DVB e da velocidade de agitação na área superficial, volume e tamanho do poro.

\begin{tabular}{|c|c|c|c|c|c|c|}
\hline $\begin{array}{c}\text { Razão } \\
\text { MMA/ } \\
\text { DVB } \\
\text { (\% molar) }\end{array}$ & $\begin{array}{l}\text { Velocidade de } \\
\text { reação } \\
(\mathbf{r p m})\end{array}$ & $\begin{array}{c}\text { Agente } \\
\text { de } \\
\text { suspensão } \\
(0,1 \% \text { da FA) }\end{array}$ & $\begin{array}{c}\text { Ferro } \\
\text { Adiciona- } \\
\text { do } \\
((\% \text { em relação } \\
\text { a quantidade de } \\
\text { monômeros }))\end{array}$ & $\begin{array}{c}\text { Área } \\
\text { Superfícial } \\
\text { BET } \\
\left(\mathbf{m}^{2} \cdot \mathbf{g}^{-1}\right)\end{array}$ & $\begin{array}{c}\text { Volume do } \\
\text { Poro } \\
\left(\mathrm{cm}^{3} \cdot \mathrm{g}^{-1}\right)\end{array}$ & $\begin{array}{c}\text { Tamanho do } \\
\text { poro } \\
\text { (̊̊) }\end{array}$ \\
\hline $50 / 50$ & 400 & gelatina & $\begin{array}{l}\text { Sem adição de ferro } \\
\text { (branco) }\end{array}$ & 231 & 0,53 & 89 \\
\hline $50 / 50$ & 400 & gelatina & 7,5 & 269 & 0,52 & 75 \\
\hline $50 / 50$ & 500 & gelatina & 7,5 & 154 & 0,41 & 107 \\
\hline
\end{tabular}

as gotas de monômeros. O agente de suspensão forma um filme protetor na superfície das gotas. Esse filme impede a coalescência e a aglomeração das gotas e das partículas de polímero formadas e, consequentemente, também poderá influenciar na incorporação do ferro na matriz polimérica, como pode ser observado na Tabela 1. A utilização da gelatina além de permitir a obtenção de partículas com tamanhos menores, também permitiu que essas partículas apresentassem tamanhos mais homogêneos. As micrografias de microscopia ótica mostraram que a distribuição de tamanho das pérolas dos copolímeros não foi uniforme e que existem diferenças de coloração entre as pérolas. Algumas se apresentam totalmente negras, outras manchadas e algumas brancas comprovando que a incorporação de ferro nas pérolas dos copolímeros também não ocorreu de forma uniforme.

A magnetização de saturação foi maior para o copolímero sintetizado com 2-hidroxietilcelulose, visto que houve maior incorporação de ferro para este copolímero (Tabela 1). Para esses materiais, também não houve formação de ciclos de histerese. Os resultados indicam valores de magnetização remanescentes próximos de zero indicando que esses copolímeros estão próximos de materiais superparamagnéticos.

\section{Efeito da velocidade de agitação na síntese dos copolímeros}

Alguns copolímeros foram sintetizados diferindo entre si no parâmetro referente à velocidade de agitação. Foram sintetizados copolímeros com velocidades de $400 \mathrm{rpm}, 300 \mathrm{rpm}$ e $500 \mathrm{rpm}$. Todas as outras condições se mantiveram constantes.

A reação com velocidade de 300 rpm não formou microesferas, ao contrário, houve a formação de um aglomerado polimérico. Por esse motivo, não foi avaliado quanto à incorporação de ferro e distribuição de tamanho de partículas e o aumento na velocidade de reação favoreceu a formação de partículas de menor tamanho (Figura 2b), sendo observadas diferenças de coloração entre as pérolas. Algumas se apresentam totalmente negras, outras manchadas e algumas brancas comprovando que a incorporação de ferro nas pérolas dos copolímeros também ocorreu de forma heterogênea. $O$ teor de ferro incorporado na reação sintetizado com velocidade de agitação de $400 \mathrm{rpm}$ foi de $52,2 \mathrm{mg}$ de $\mathrm{Fe} / \mathrm{g}$ de copolímero enquanto que a reação sintetizada com velocidade de agitação de $500 \mathrm{rpm}$ foi 57,0 mg de Fe/g de copolímero (Tabela 1).

As micrografias de microscopia eletrônica de varredura mostraram os perfis da superfície externa e interna do copolímero sintetizado com velocidade de $500 \mathrm{rpm}$. Foi possível observar que existiam algumas aglomerações de partículas de ferro em pontos distintos da superfície e algumas partículas de ferro da superfície do copolímero estão recobertas por uma fina camada de polímero. No entanto, não se pode afirmar que haja a presença de ferro no interior desses copolímeros.

A Figura 3b mostra o gráfico de magnetização do copolímero sintetizado com velocidade de $500 \mathrm{rpm}$. Pode-se verificar um aumento significativo na magnetização de saturação de 8,8 emu. $\mathrm{g}^{-1}$ para o copolímero sintetizado com velocidade de $400 \mathrm{rpm}$ para 13,0 emu. $\mathrm{g}^{-1}$ para o copolímero sintetizado com velocidade de $500 \mathrm{rpm}$. Este aumento pode ser explicado pelo aumento de ferro incorporado neste copolímero. A incorporação do ferro no material polimérico se apresenta de forma irregular com relação ao tamanho das esferas. Esta aglomeração produziu uma heterogeneidade na distribuição das partículas de ferro, interferindo na análise. A magnetização de saturação depende exclusivamente da quantidade de ferro na amostra já que a unidade de medida é relativa à massa.

A Tabela 1 mostra também a influência da velocidade de reação na magnetização de saturação, magnetização remanescente na coercividade dos copolímeros de MMA/DVB. Analisando esses resultados verificamos um decréscimo na força coerciva ou coercividade. Esse fato pode ser explicado pela diminuição do tamanho das partículas no copolímero sintetizado com velocidade de $500 \mathrm{rpm}$. A coercividade ou força coerciva (Hc) é o campo reverso necessário para reduzir a magnetização de saturação para zero. A magnitude de $\mathrm{H}_{\mathrm{C}}$ é afetada pelo tamanho de partícula e pela homogeneidade de cada material. Verificamos também valores de magnetização remanescentes próximos de zero indicando que esses copolímeros estão próximos de materiais superparamagnéticos.

Os resultados obtidos das análises de área superficial BET, volume de poros BJH e tamanho dos poros para os copolímeros sintetizados com velocidade de agitação de 400 e 500 rpm estão descritos na Tabela 2. Verifica-se que o aumento da velocidade de agitação causou um decréscimo na área superficial e um aumento no tamanho de poros. As curvas de adsorção e de dessorção de nitrogênio copolímero sintetizado com velocidade de agitação de $500 \mathrm{rpm}$ assemelham-se à isoterma do tipo IV, característico de materiais mesoporosos ${ }^{[14]}$.

\section{Conclusão}

Foi possível sintetizar microesferas poliméricas à base de MMA-DVB com boas propriedades magnéticas (magnetização de saturação $=13$ emu. $\mathrm{g}^{-1}$ ) e bom controle morfológico esférico usando gelatina como agente de suspensão $(1 \% \mathrm{~m} / \mathrm{v})$, razão molar MMA/DVB 50/50, 7,5\% de Ferro e velocidade de 500 rpm. Estes materiais não apresentaram ciclos de histerese, estando próximos de materiais com propriedades superparamagnéticas. As micrografias de microscopia eletrônica de varredura mostraram que as partículas de ferro ficaram localizadas apenas na superfície das microesferas poliméricas. No interior das pérolas, pode-se observar a formação 
de aglomerados de microesferas de diferentes tamanhos, enquanto na superfície, os domínios poliméricos são estruturas compactas e sem forma definida, características comuns de polímeros reticulados macroporosos sintetizados através de polimerização em suspensão.

\section{Agradecimentos}

Os autores agradecem ao CNPq e a FAPERJ pelo apoio financeiro, ao Eng. Eduardo Castello Branco pelas análises de ASAP e ao Sr. Alan Cesar do IBRAG/UERJ pelas análises de SEM.

\section{Referências Bibliográficas}

1. Lan, F.; Lui, K. X.; Jiang, W.; Zeng, X. B.; Wu, Y. \& Gu, Z. W. - Nanotechnology, 22, p.225604 (2011). Disponível em: <http:// www.ncbi.nlm.nih.gov/pubmed/21454944>. Acesso em: 28 jun. 2011.

2. Sun, Y.; Ma, M.; Zhang, Y. \& Gu, N. - Colloids Surf., 245, p.15 (2004) http://dx.doi.org/10.1016/j.colsurfa.2004.05.009

3. Choi, J. S.; Park, B. J.; Cho, M. S. \& Choi, H. J. - J. Magn. Magn. Mater., 304, p.374 (2006). http://dx.doi.org/10.1016/j.jmmm.2006.02.055

4. Lee, Y.; Rho, J.; Jung, B. - J. Appl. Polym. Sci., 89, p.2058 (2002) http://dx.doi.org/10.1002/app.12365

5. Philippova, O.; Barabanova, A.; Molchanov, V. \& khokhlov, A. - J. Eur. Polym., 47,p. 542 (2011) http://dx.doi.org/10.1016/j. eurpolymj.2010.11.006
6. Men'shikova A. Y. U.; Shabsel's, B. M.; Shurkis, Y. U. O.; Inskin K S.; Chekina, N. A. \& Ivanchev, S. S. - Russ. J. Gen. Chem., 77, p.354 (2007).

7. Yeom, S. H.; Daugulis, A. J. \& Lee, S. Y. - Process Biochem., 45 p.1582 (2010) http://dx.doi.org/10.1016/j.procbio.2010.06.017

8. Chen, M.; Lin, Z. \& Qian, H. - Chin. Chem. Lett., 19, p.1495 (2008) http://dx.doi.org/10.1016/j.cclet.2008.09.050

9. Bo, Z.; Jranmin, X. \& Huizhou, L. - Chem. Eng. China, 96, p.1 (2007)

10. Men'shikova, A. Y. U.; Shabsel's, B. M.; Shurkis, Y. U. O.; Inskin, K. S.; Chekina, N. A. \& Ivanchev, S. S. - Russ. J. Gen. Chem., 77, p.354. (2007)

11. Rabelo, D. \& Coutinho, F. M. B. - Polym. Bull., 31, p.585 (1993) http:// dx.doi.org/10.1007/BF00297896

12. Costa, C. N. - "Síntese e Caracterização de copolímeros à base de poli(metacrilato de metila) e divinilbenzeno com propriedades magnéticas", Dissertação de Mestrado, Universidade do Estado do Rio de Janeiro, Brasil (2010)

13. Conceição, B. M.; Costa, M. A. S.; Santa-Maria, L. C.; Silva, M. R.; Hui, W. S. - Polímeros, 21, p.409 (2011)

14. Teixeira, V. G.; Coutinho, F. M. B. \& Gomes, A. S.- Quim. Nova, 6 , p.808 (2001).

Enviado: $28 / 06 / 11$

Reenviado: $22 / 08 / 11$

Aceito: $02 / 09 / 11$ 